\title{
Chalcone Scaffold based Antimycobacterial Agents
}

\author{
Fliur Macaev ${ }^{1 *}$, Veaceslav Boldescu ${ }^{1,2}$, Serghei Pogrebnoi ${ }^{1}$ and Gheorghe Duca ${ }^{1}$ \\ ${ }^{1}$ Laboratory of Organic Synthesis, Institute of Chemistry of ASM, MD2028 Chişinău, Moldova \\ ${ }^{2}$ Faculty of Chemistry and Chemical Technology, Moldova State University, MD2009 Chişinău, Moldova
}

\begin{abstract}
This article represents a mini-review dedicated to chalcone derivatives with antimycobacterial activity. Natural and synthetic chlacones are reviewed. General and specific schemes of synthesis of chalchone derivatives are presented. QSAR and docking studies of certain chalcones are analyzed in respect of their antimycobacterial activity and inhibition of Mycobacterium tuberculosis enzymes.
\end{abstract}

Keywords: Antimycobacterial compounds; Chalcone derivatives; Docking; Tuberculosis; QSAR

\section{Introduction}

Chalcones structurally represent open-chain flavonoids in which the two aromatic rings are joined by a three-carbon $\alpha, \beta$-unsaturated carbonyl system (1,3-diphenyl-2-propen-1-one). In the plants, they are considered to be precursors of flavonoids and isoflavonoids. Chalcones are known to posses different types of biological activity: antileishmanial, anti-inflammatory, antimitotic, anti-invasive, anti-fungal, CyLT1 (LTD4) receptor antagonism, anti-malarial, anti-plasmodial, immunosupressive, cytotoxic, anti-tumor, and anti-oxidant properties, and modulation of P-glycoprotein-mediated multi-drug resistance [13].

This mini-review is dedicated to chalcones with antimycobacterial activity with analysis on their structure-activity relationships and results of some docking studies. The review has as its main purpose analysis and generalization of the data obtained so far on chalcone derivatives with activity against Mycobacterium tuberculosis. We hope it will help to further development of new cheap and effective antimycobacterial medicines so much needed by the contemporary medicine.

\section{Natural Chalcones with Antimycobacterial Activity}

A number of naturally derived chalcones have been identified to exhibit amtimycobacterial activity. Thus, a study of natural derived chalcones has revealed that M. tuberculosis, M. avium and M. bovis are strongly inhibited by licochalcone 1 (Figure 1) obtained from Glycyrrhiza inflate with low MICs in the range of $15-60 \mu \mathrm{M}$ (MIC of the control rifampicin $<2.5 \mu \mathrm{M})[4,5]$.

Another study of chalcones derived from Dorstenia barteri, a small herb from tropical regions of South America, has demonstrated that isobachalcone 2 and stipulin 3 (Figure 2) possess a high level of antimycobacterial activity, with 2 being the most active [6].

\section{Synthetic Chalcones with Antimycobacterial Activity}

Chalcone derivatives can be easily synthesized according to the scheme 1 . This is a general scheme of synthesis for chalcones. This way, Sivakumar et al. [7] have synthesized 25 chalcone derivatives and performed QSAR studies of their antimycobacterial activity. According to their results introduction of - $\mathrm{NMe}_{2},-\mathrm{OMe},-\mathrm{SMe}$ groups in different positions of the ring $\mathrm{B}$ led to the increase of anti-tuberculosis activity as compared to unsubstituted chalcone. At the same time, introduction of the hydrophilic groups $-\mathrm{OH}$ and $-\mathrm{NO}_{2}$ in the ring A also enhances anti-mycobacterial activity. Halogen substitution in positions $\mathrm{R}^{1}$ and $\mathrm{R}^{3}$ of the ring A reduces the activity of the resulted derivatives. Nitro- and methoxy-substitution in position $\mathrm{R}^{3}$ also has negative effect on antituberculosis activity.
Most active of the compounds studied by Sivakumar et al. [7], with $>90 \%$ inhibition at $160-197 \mu \mathrm{M}$, are presented in the table below (Table 1). From this, one can observe that the most active is compound 7 with $98.90 \%$ inhibition. Antimycobacterial activity of the tested compounds under this study was evaluated by luciferase reporter phage assay method against $M$. tuberculosis $\mathrm{H}_{37} \mathrm{R}_{v}$ and the observed inhibition percentage was presented. A compound was considered to be an antimycobacterial agent if fifty percent reduction in the Relative Light Units (RLU) is observed when compared to the control using a luminometer.

Lin et al. [8] performed an extensive screening of chalcones' antimycobacterial properties in vitro. Compounds with a hydroxyl group in position 2 of the ring $\mathrm{A}$ and a halogen substituent (chloro or iodo) in position 3' of the ring B (Figure 3 ) demonstrated the strongest activity with inhibition $90-92 \%$ at concentrations $36-48 \mu \mathrm{M}$.

It has also been determined that initial 2-hydroxy-chalcone's<smiles>C=CC(C)(C)c1cc(/C=C/C(=O)c2ccc(O)cc2)c(OC)cc1O</smiles>

1

Figure 1: Licochalcone A structure.
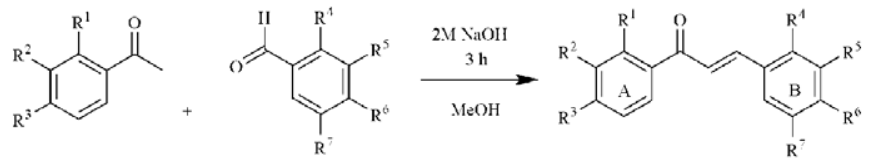

Scheme 1: General scheme of synthesis of chalcone derivatives [7].

*Corresponding author: Fliur Macaev, Laboratory of Organic Synthesis, Institute of Chemistry of ASM, Academiei str. 3, MD-2028 Chisinau, Moldova, Tel: +37322 739754; Fax: 37322 739954; E-mail: flmacaev@cc.acad.md

Received April 26, 2014; Accepted May 19, 2014; Published May 21, 2014

Citation: Macaev F, Boldescu V, Pogrebnoi S, Duca G (2014) Chalcone Scaffold based Antimycobacterial Agents. Med chem 4: 487-493. doi:10.4172/21610444.1000183

Copyright: $\odot 2014$ Macaev F, et al. This is an open-access article distributed under the terms of the Creative Commons Attribution License, which permits unrestricted use, distribution, and reproduction in any medium, provided the original author and source are credited. 
<smiles>CC(C)=CCc1c(O)ccc(C(=O)/C=C/c2ccc(O)cc2)c1O</smiles>

2<smiles>CC(C)=CCc1cc(/C=C/C(=O)c2cc(CC=C(C)C)c(O)cc2O)ccc1O</smiles>

3

Figure 2: Isobachalchone 2 and stipulin 3 structures.<smiles>[Z2]c1ccc(/C=C/C(=O)c2ccc([Y])c([Z1])c2[Y])c([Y])c1[Z17]</smiles>

\begin{tabular}{|c|c|c|c|c|c|c|c|c|}
\hline Compound & $\mathbf{R}^{\mathbf{1}}$ & $\mathbf{R}^{\mathbf{2}}$ & $\mathbf{R}^{\mathbf{3}}$ & $\mathbf{R}^{\mathbf{4}}$ & $\mathbf{R}^{\mathbf{5}}$ & $\mathbf{R}^{\mathbf{6}}$ & $\mathbf{C}^{\mathbf{\mu} M}$ & \% reduction in RLU \\
\hline $\mathbf{4}$ & $\mathrm{H}$ & $\mathrm{NO}_{2}$ & $\mathrm{H}$ & $\mathrm{OMe}$ & $\mathrm{H}$ & $\mathrm{OMe}$ & 160 & 92.19 \\
\hline $\mathbf{5}$ & $\mathrm{H}$ & $\mathrm{NO}_{2}$ & $\mathrm{H}$ & $\mathrm{H}$ & $\mathrm{H}$ & $\mathrm{NMe}_{2}$ & 169 & 90.06 \\
\hline $\mathbf{6}$ & $\mathrm{H}$ & $\mathrm{H}$ & $\mathrm{NO}_{2}$ & $\mathrm{OMe}$ & $\mathrm{H}$ & $\mathrm{H}$ & 177 & 94.30 \\
\hline $\mathbf{7}$ & $\mathrm{H}$ & $\mathrm{OH}$ & $\mathrm{H}$ & $\mathrm{H}$ & $\mathrm{H}$ & $\mathrm{OMe}$ & 197 & 98.90 \\
\hline
\end{tabular}

*RLU- Relative Light Units

Table 1: Chalcone derivatives studied by Sivakumar et al. [7].<smiles>O=C(/C=C/c1cccc(Cl)c1)c1ccccc1O</smiles><smiles>O=C(/C=C/c1cccc(I)c1)c1ccccc1O</smiles>

Figure 3: Chalcones with $90 \% 8$ and $92 \% 9$ inhibition of $M$. tuberculosis at concentrations of 48 and $36 \mu \mathrm{M}$ respectively [8].

inhibition activity against $M$.tuberculosis is equal to $61 \%$. However, introduction of methoxy or chloro group in position 4 of the A ring increases the antimycobacterial activity up to $78 \%$ and $89 \%$ respectively. A bromo or iodo substituent in the same position decreased the activity of the respective derivatives [8].

Introduction of substituents in the position 5 of the 2-hydroxychalcone's ring A also has different consequences. Thus, the activity increases for $\mathrm{Cl}$ (67\%), $\mathrm{Br}(68 \%)$, phenyl (68\%) derivatives, and decreases for I (51\%), $\mathrm{NH}_{2}$ (6\%) derivatives. Interestingly, for halogen substituents most preferable position in the ring A of 2-hydroxychalcone varies depending on their nature. Hence, for $\mathrm{Br}$ most preferable position is 3 , for $\mathrm{Cl}$ - position 4 , and for $\mathrm{I}$ - position 5 . Introduction of an additional substituent to the rings A or B of the above described 2-hydroxy-chalcones led to the decrease or total loss of the anti-TB activity [8].

Introduction of halogen substituents in the ring B of the 2-hydroxychalcone increased the antimycobacterial activity. Compounds with a halogen substituent at the position 3 demonstrated stronger activity than those with a halogen substituent at the position 2 or 4 . Of all the halogen compounds, no fluoro-substituted compounds were investigated under that research [8].

\section{Inhibitors of Mycobacterial Protein Tyrosine Phosphatase A}

The tyrosine phosphatase from Mycobacterium tuberculosis is an essential virulence factor that mediates mycobacterial survival in the host, being secreted by the mycobacteria into the cytoplasm of macrophages [9].

A group of naphthylchalcone derivatives have been studied for their inhibitory properties against $M$. tuberculosis protein tyrosine phosphatase A (MtbPtpA) [10,11]. SAR studies and molecular modeling of the studied compounds binding to the active site in MtbPtpA has demonstrated that $o, m$-methoxy substitution patterns of the A-ring, and the 2-naphthyl group as B-ring play important roles in orientating the inhibitors within the active site of the enzyme. Further molecular modifications have been proposed by the authors. These include replacement of a hydrophobic group at the $p$-position of A-ring, supposed to interact to the side chain of Cys-16 and Ile-15; and substitution of the naphthyl moiety with an electron-rich heterocycle group (e.g., indole, quinoline, quinoxaline) [11].

Study of the naphthylchalcone derivatives activity and toxicity against THP-1 macrophages has shown that compounds 10 and 12 (Tables 2 and 3) being most active also determined high level of toxicity against the macrophagial cells. At the same time compound 11 has not demonstrated any toxic effects against human macrophages and demonstrated 50\% inhibition of $M$. tuberculosis growth. A delayed effect has been determined for the compounds 13 and 14 [11].

Further studies on M. tuberculosis PtpA inhibitors have confirmed that, in general, the 2-naphthyl group as B-ring favorably contributes 
<smiles>[R]c1ccc([X])c(C(=O)/C=C/c2cccc3ccccc23)c1</smiles>

\begin{tabular}{|c|c|c|}
\hline Compound & $\mathbf{R}^{1}$ & $\mathbf{R}^{\mathbf{2}}$ \\
\hline $\mathbf{1 0}$ & $-\mathrm{OCH}_{3}$ & $-\mathrm{OCH}_{3}$ \\
\hline $\mathbf{1 1}$ & $-\mathrm{OH}$ & $-\mathrm{H}$ \\
\hline
\end{tabular}

Table 2: 1-Naphthylchalcone derivatives studied by Mascarello et al. [11].<smiles>[R]c1cc(C(=O)/C=C/c2ccc3ccccc3c2)c([R])c([R])c1[R]</smiles>

\begin{tabular}{|c|c|c|c|c|}
\hline Compound & $\mathbf{R}^{\mathbf{3}}$ & $\mathbf{R}^{\mathbf{4}}$ & $\mathbf{R}^{\mathbf{5}}$ & $\mathbf{R}^{\mathbf{6}}$ \\
\hline $\mathbf{1 2}$ & $-\mathrm{OCH}_{3}$ & $-\mathrm{H}$ & $-\mathrm{H}$ & $-\mathrm{OCH}_{3}$ \\
\hline $\mathbf{1 3}$ & $-\mathrm{H}$ & $-\mathrm{OCH}_{3}$ & $-\mathrm{OH}$ & $-\mathrm{H}$ \\
\hline $\mathbf{1 4}$ & $-\mathrm{H}$ & $-\mathrm{OCH}_{3}$ & $-\mathrm{OCH}_{3}$ & $-\mathrm{H}$ \\
\hline
\end{tabular}

Table 3: 2-Naphthylchalcone derivatives studied by Mascarello et al. [11].

to MtbPtpA inhibition. Thus, among the most active inhibitors of MtbPtpA studied by Chiaradia et al. [12] compound 15 (Figure 4) demonstrated the second best result in the inhibitory activity tests. This observation supports the previously obtained data on significant $\pi-\pi$ interactions between the 2-naphthyl substituent and the side chain of the Trp48 amino acid residue of the MtbPtpA binding site. The most active MtbPtpA inhibitor among the chalcone derivatives covered by this study was the compound 16 with IC $50=15 \mu \mathrm{M}$, which represents a derivative of benzylated vanillin with two metoxy groups in positions 2 and 4 of the ring $A$ (Figure 4).

As a conclusion authors of the [12] study concluded that the hydrophobicity of the B-ring along with the presence of hydrogen bond donor/acceptor substituents in the A-ring seem to play an important role in the inhibitory activity of the studied series of compounds.

The most active of M. tuberculosis protein tyrosine phosphatase B (MtbPtpB) inhibitors determined by this study were compounds 17 $(\mathrm{IC} 50=25 \mu \mathrm{M})$ and $18(\mathrm{IC} 50=12 \mu \mathrm{M})$ (Figure 5). The crystallographic binding mode of the 18 indicated that the carboxylic acid substituent in the ring $\mathrm{B}$ is important for ligand binding and affinity. The 2-naphthyl substituent also seems to play an important role in the inhibition of MtbPtpB, regardless of whether it is A-ring, as in 18, or B-ring, as in 17. As well, it was determined that the presence of bulky (compound 17) or electron withdrawing (compound 18) substituents in the phenyl group (B-ring) is favorable for the inhibitory potency.

Additional studies on the selectivity of action of the most active among the detected MtbPtpA and MtbPtpB inhibitors was performed against the human tyrosine phosphatase (PTP1B). The obtained data showed maximum selectivity index for the MtbPtpB inhibitor 18 $(\mathrm{SI}=258)$. The highest selectivity among the active MtbPtpA inhibitors demonstrated compound 16 (SI=18).

\section{Inhibitors of Mycobacterial Dihydrofolate Reductase}

One promising drug target for treatment of mycobacterial infections is dihydrofolate reductase, an enzyme in that catalyzes the reduction of dihydrofolate to tetrahydrofolate. The latter is necessary for the one-carbon transfer reactions used in the biosynthesis of nucleic and amino acids including thymidylate, adenine, methionine, glycine, and histidine. By halting the synthesis of these DNA, RNA, and protein subunits, DHFR inhibitors arrest the cell growth.

As dihydrofolate reductase inhibitors, methylpyrrolidinyl chalcones (Figure 6) have been studied [13]. According to the findings of Gond et al., there are strong chances of involvement of residues Asp-27, Ser-49, Ile-94, Gly-96, and Tyr-100 of M. tuberculosis DHFR in inhibition. Also, it has been determined that hydrophobic forces might play an important role in inhibition of bacterial DHFR and certain functional groups might be responsible for hydrophobic effect of chalcone derivatives. Among these, methoxyphenyl ethanone group has been claimed by authors to be for the first time determined to be have hydrophobic involvement in stabilization process of inhibitorenzyme complex.<smiles>O=C(/C=C/c1ccc2ccccc2c1)c1ccc(Cl)s1</smiles>

15<smiles>COc1ccc(C(=O)/C=C/c2ccc(OCc3ccccc3)c(OC)c2)c(OC)c1</smiles>

16

Figure 4: M. tuberculosis PtpA inhibitors [12]<smiles>O=C(/C=C/c1ccc2ccccc2c1)c1ccc(Br)cc1</smiles>

17<smiles>O=C(O)c1ccc(/C=C/C(=O)c2ccc3ccccc3c2)cc1</smiles>

18

Figure 5: M. tuberculosis PtpB inhibitors [12] 
<smiles></smiles>

$\mathrm{R}=\mathrm{Br}, \mathrm{Cl}, \mathrm{F}, \mathrm{OMe}, \mathrm{Me}$, methylfuran

Figure 6: Methylpyrrolidinyl chalcones inhibitors of $M$. tuberculosis dihydrofolate reductase [13].

\section{Inhibitors of Mycobacterial Enoyl Reductase}

The enoyl-acyl carrier protein reductase (ENR) is involved in bacterial fatty acid biosynthesis and is the target of the front-line antituberculosis drug isoniazid and of other antibacterial compounds.

Chalcone derived ENR inhibitors studied by Yadav et al. [14] proved to have high affinity to the envisaged enzyme. All the active chalcone derivatives covered by this study showed good binding affinity as compared with the standard inhibitors of ERN: triclosan and isoniazid. The molecular docking results of these compounds showed that the main amino acid residues involved in inhibition are hydrophobic in nature. These include aliphatic (Gly-93 and Ile-200), sulfur containing (Met-159 and Met-206), cyclic (Pro-191), aromatic (Tyr-146, Tyr-156, and Phe-203), and basic (Lys-163) residues. In general, main influencing factors of molecular interactions between ENR and chalcone derivatives determined by this study were H-bond, hydrophobic, and electrostatic interactions.

\section{Other Inhibitors of Mycobacterial Growth}

Acetylenic chalcones studied by [15] did not show high levels of antimycobacterial activity. Of these, only two compounds 19 and 20 (Figure 7) gave somewhat promising results with MIC around $31 \mu \mathrm{M}$ under in vitro activity test against $M$. tuberculosis $\mathrm{H}_{37} \mathrm{Rv}$ strain.

Due to the high content of lipids in the mycobacterial cell wall, it is considered that one of the important characteristics of the antimycobacterial compounds would be their lipophilicity [16]. However, in several works $[7,15]$ it has been proved that there is no direct connection between the lipophilicity of the molecule and its antimycobacterial properties.

Ahmad et al. [17] have studied anti-TB properties of chalcone derivatives of type I and certain conformationally restricted chalcone analogues of type II (Figure 8).

The synthesis of these compounds differs from the traditional scheme of synthesis for other chalcone derivatives and is further presented. The type I chalcone derivatives were obtained according to the scheme 2. In short, the synthesis starts from Friedel-Crafts acylation of anisol with phenylacetic acid using polyphosphoric acid (PPA) at $100^{\circ} \mathrm{C}$ and yields with deoxybenzoin derivative. The latest in reaction with 4-hydroxybenzaldehyde in presence of piperidine and dry benzene at reflux gives compound 21 , which on condensation with ethyl bromoacetate forms corresponding ester derivative 22 . After hydrolysis of 22 under basic reaction conditions corresponding carboxylic acid 23 is formed. The following treatment of acid 23 with different amines in presence of 1-hydroxy benzotriazole (HOBt) and dicyclohexylcarbodiimide (DCC) in $\mathrm{CH}_{2} \mathrm{Cl}_{2}$ under basic reaction conditions at reflux gives amide derivatives of chalcone $24 \mathrm{a}$ and $24 \mathrm{~b}$.

The type II chalcone derivatives were obtained according to the scheme 3 . In brief, compound 25a is subjected to condensation with 4-hydroxybenzaldehyde (26a) in presence of piperidine and dry benzene under reflux to afford 1-(2-hydroxy-4-methoxy-phenyl)-3(4-hydroxy-phenyl)-propenone (27a), which in reaction with phenyl acetic acid in acetic anhydride and triethyl amine at reflux gives 7-methoxy-3-phenyl-4\{2-[4-acetoxy-phenyl]-vinyl $\}$-benzopyran-2one (28a). After hydrolysis of 28a in $2 \%$ methanolic $\mathrm{NaOH}, 7$-methoxy3-phenyl-4\{2-[4-hydroxy-phenyl]-vinyl\}-benzopyran-2-one 30 is formed. Condensation of compound 30 with 2-chloroethyl alkylamines hydrochlorides in acetone in presence of $\mathrm{K}_{2} \mathrm{CO}_{3}$ under reflux gives products $31 \mathrm{a}-\mathrm{c}$. Similarly, compound 29 can be synthesized by reaction of $28 \mathrm{~b}$ using same sequence of reactions.<smiles>C#CCOc1ccccc1C(=O)/C=C/c1ccc(OC)cc1</smiles>

19<smiles>C#CCOc1ccc(C(=O)/C=C/c2ccc(OC)cc2OC)cc1</smiles>

20

Figure 7: Acetylenic chalcones studied by [15].<smiles>[R]N([R8])C(=O)COc1ccc(/C=C(/C(=O)c2ccc(OC)cc2)c2ccccc2)cc1</smiles>

type I<smiles>[R8]N([R])CCOc1ccc(/C=C/c2c(-c3ccccc3)c(=O)oc3cc(OC)ccc23)cc1</smiles>

1ype II

Figure 8: Chalcone derivatives of type I and conformationally restricted chalcone analogues of type II active against M. tuberculosis [17]. 
<smiles>[R]N([R])C(=O)COc1ccc(/C=C(\C(=O)c2ccc(OC)cc2)c2ccccc2)cc1</smiles>

$24 \mathrm{a} \mathrm{R}-\mathrm{H} . \mathrm{R}^{1}-\mathrm{C}_{2}-\mathrm{C}_{2}-\mathrm{CH}_{2}-\mathrm{CH}_{3}$

$24 \mathrm{~b} \mathrm{R}-\mathrm{CH}_{3}, \mathrm{R}^{1}-\mathrm{CH}_{2}-\mathrm{CH}_{2}-\mathrm{C}_{2}-\mathrm{CH}_{3}$

Scheme 2: Synthesis of chalcone derivatives [17]. Reagents and conditions: (a) PPA, heating at $100{ }^{\circ} \mathrm{C}$; (b) 4-hydroxybenzaldehyde, piperidine, dry benzene, reflux; (c) ethyl bromoacetate, anhy. $\mathrm{K}_{2} \mathrm{CO}_{3}$, dry acetone, reflux; (d) $\mathrm{NaOH}$, methanol, reflux; (e) alkylamines, DCC, $\mathrm{HOBt}, \mathrm{DMAP}, \mathrm{CH}_{2} \mathrm{Cl}_{2}$, reflux.

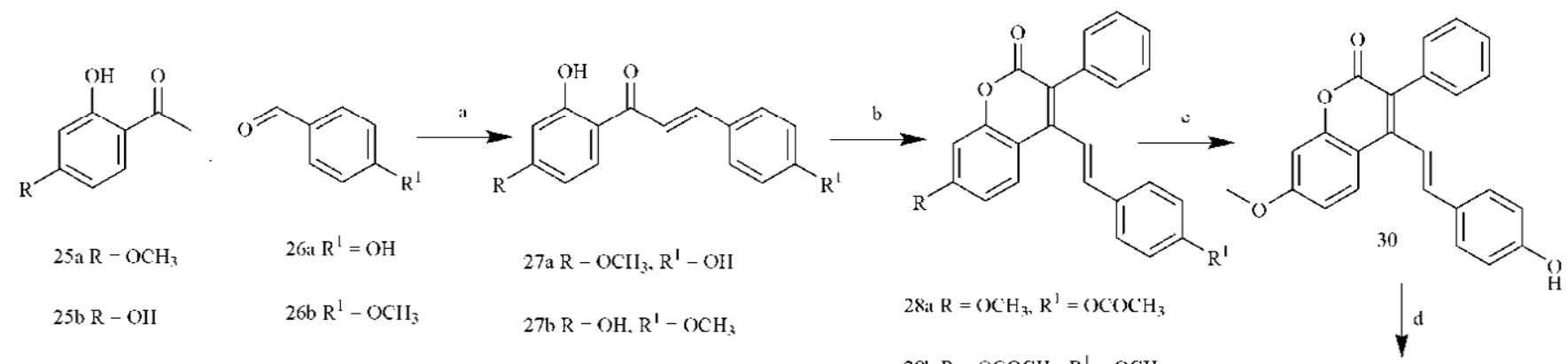

$28 \mathrm{~b} \mathrm{R} \quad \mathrm{OCOCII}_{2} \mathrm{R}^{1} \quad \mathrm{OCHI}_{3}$<smiles></smiles>

Scheme 3: Synthesis of conformationally restricted chalcone analogues [17]. Reagents and conditions: (a) piperidine, dry benzene, reflux; (b) phenylacetic acid, Et3N acetic anhydride, reflux; (c) $2 \% \mathrm{NaOH} / \mathrm{MeOH}$, r.t.; (d) 2-chloroethyl alkyl amines hydrochlorides, anhy. K2CO3, dry acetone, reflux.

A group of aryloxy azoyl chalcones (Figure 9) were screened for antimycobacterial activity by the group of Marrapu et al. [18]. The screen data showed that chalcones with azolyl moiety in ring $\mathrm{A}$ and aryloxyl moiety in ring B showed the MIC of 1.9 - $30 \mu \mathrm{M}$ against $M$. tuberculosis $\mathrm{H}_{37} \mathrm{R}_{v}$. Similar levels of activity were demonstrated by chalcones with aryloxyl moiety in ring A and azolyl moiety in ring B. At the same time, chalcones with 4-imidazolyl moiety were found to be more active than their triazolyl counterparts except one compound with 1,2,4-triazolyl group in ring $B$ and a 3-chlorobenzyloxy group in ring $\mathrm{A}$, which showed a MIC value of $1.9 \mu \mathrm{M}$.

Further, analysis of the aryloxy azoyl chalcones activity detected that substitution of the benzyloxy group with 2- $\mathrm{NO}_{2}$-aryloxy or $4-\mathrm{CF}_{3}-$ aryloxy group led to loss of activity with MIC values of $28-29 \mu \mathrm{M}$ indicating that the presence of the benzyloxy group is essential for antitubercular activity. Replacement of different halogen substituents 
<smiles>[R]c1ccc(C(C)(C)C(C)(C)Oc2ccc(/C=C/C(=O)c3ccc(-n4cncn4)cc3)cc2)cc1</smiles><smiles>[R]c1ccc(C(C)(C)C(C)(C)Oc2ccc(C(=O)/C=C/c3ccc(-n4cncn4)cc3)cc2)cc1[R]</smiles>

Figure 9: Aryloxy azoyl chalcones obtained and tested by [18]. Legend: $\mathrm{R}_{1}=2-\mathrm{Cl}, 3-\mathrm{Cl}, 2-\mathrm{F}$ or 2- $\mathrm{NO}_{2} ; \mathrm{R}_{2}=4-\mathrm{Cl}, 5-\mathrm{Cl}, 4-\mathrm{F}, 5-\mathrm{F}, 4-\mathrm{CF}_{3}$ or $\mathrm{H} ; \mathrm{X}=\mathrm{CH}$ or $\mathrm{N} ; \mathrm{n}=0$ or 1 .<smiles>O=C(/C=C/c1ccc(OCc2ccc(Cl)cc2Cl)cc1)c1ccc(-n2ccnc2)cc1</smiles><smiles>O=C(/C=C/c1ccc(-n2ccnc2)cc1)c1ccc(OCc2ccc(F)cc2F)cc1</smiles>

Figure 10: Aryloxy azoyl chalcones with $99 \% 32$ and $71 \% 33$ inhibition of $M$. tuberculosis at concentration of 27 and $30 \mu \mathrm{M}$ respectively [18]<smiles>COc1cccc(/C=C/C(=O)c2ccc(Nc3cnc4cc(Cl)ccc4c3)cc2)c1OC</smiles>

34<smiles>COc1ccc(OC)c(/C=C/C(=O)c2ccc(Nc3cnc4cc(Cl)ccc4c3)cc2)c1</smiles>

35

Figure 11: Quinolinyl chalcones with high inhibition of M. tuberculosis at concentration of $28 \mu \mathrm{M}$ [19].

in the benzyloxy moiety did not lead to any significant change in activity, but influenced the cytotoxicity of the resulted compounds against VERO cells and mouse bone-marrow derived macrophages. The most active compounds determined in this assay were compound 32 (with an imidazolyl moiety in ring A and a 2,4-dichlorobenzyloxy moiety in ring B), which demonstrated $99 \%$ inhibition of intracellular bacilli growth, and compound 33 (with an imidazolyl moiety in ring $\mathrm{B}$ and a 2,4-difluorobenzyloxy moiety in ring A), which displayed $71 \%$ inhibition (Figure 10). In vivo oral efficacy studies of these compounds against $M$. tuberculosis $\mathrm{H}_{37} \mathrm{R}_{v}$ in mice demonstrated that compound 33 exhibited moderate activity with a marginal protection of $40 \%$ against virulent $M$. tuberculosis, while for compound 32 it was only $13 \%$.

Mono and bis benzyloxy, bis imidazolyl, and bis triazolyl chalcone derivatives obtained and screened under this study did not show any antimycobacterial activity.

A good level of antimycobacterial activity demonstrated some of the substituted quinolinyl chalcones studied by Sharma et al. [19]. The 2,3-dimethoxyphenyl 34 and 2,5-dimethoxyphenyl 35 substituted derivative of quinolinyl chalcones were found to be active against $M$. tuberculosis and showed MIC of $28 \mu \mathrm{M}$ (Figure 11). At the same time toxicity tests of these two compounds against VERO cells and mouse bone-marrow derived macrophages showed that they are non toxic.

A QSAR study to predict antimycobacterial activity of different chalcones has also been performed [20]. Under this study, QSAR equations have been developed with the four parameters hardness $(\eta)$, $E_{\text {номо }}, \mathrm{MR}_{\mathrm{A}-4}$ and $\mathrm{MR}_{\mathrm{B}-4^{4}}$ that provide regression models to predict the activity of the set of chalcone molecules against M. tuberculosis $\mathrm{H}_{37} \mathrm{R}_{v}$. These regression models reveal that in gas phase, higher values of $\eta$ and lower values of $E_{\text {Номо }}, \mathrm{MR}_{\mathrm{A}-4}$ and $\mathrm{MR}_{\mathrm{B}-4^{4}}$ of chalcones increase their inhibitory activities against $M$. tuberculosis $\mathrm{H}_{37} \mathrm{R}_{v}$. At the same time, it has been detected that in solvent phase lower values of $\eta, E_{\text {Номо }}, \mathrm{MR}_{\mathrm{A}-4}$ and higher value of $\mathrm{MR}_{\mathrm{B}-4}$, increase the antimycobacterial activity of chalcones.

\section{Conclusions}

A large variety of natural and synthetic chalcones possess antimycobacterial activity. In vitro and in silico studies of their activity have suggested that one of the important factors influencing the antituberculosis activity of chalcones is lipophilicity of their molecules that allows them to easily penetrate the mycobacterial cell wall. Presence of hydrophobic groups as substituents in chlacones' rings A and B is also important for better affinity towards the enzymes they inhibit. So far a number of chalcones proved to have a high inhibition activity against M. tuberculosis in low concentrations with proved low cytotoxicity against human cells. Simplicity of their synthesis and a low cost of the process are among the other important advantages of chalcones' as potential anti-tuberculosis. Hence, chalcones have a big potential as future anti-tuberculosis agents and their research in this field should continue for further development into new medicines.

\section{Acknowledgements}

The authors are grateful for the funding of this research under the Moldovan State Program project 14.518.04.08A.

\section{References}

1. Sahu NK, Balbhadra SS, Choudhary J, Kohli DV (2012) Exploring pharmacological significance of chalcone scaffold: a review. Curr Med Chem 19: 209-225. 
Citation: Macaev F, Boldescu V, Pogrebnoi S, Duca G (2014) Chalcone Scaffold based Antimycobacterial Agents. Med chem 4: 487-493. doi:10.4172/2161-0444.1000183

2. Bukhari SN, Jasamai M, Jantan I (2012) Synthesis and biological evaluation of chalcone derivatives (mini review). Mini Rev Med Chem 12: 1394-1403.

3. Sahu U, Panda NC, Ravikumar BVV, Kumar A (2014) Activity of chalcone and its derivatives - a review. PharmaTutor 2: 62-75.

4. Kanokmedhakul S, Kanokmedhakul K, Phonkerd N, Soytong K, Kongsaeree $\mathrm{P}$, et al. (2002) Antimycobacterial anthraquinone-chromanone compound and diketopiperazine alkaloid from the fungus Chaetomium globosum KMITL-N0802. Planta Med 68: 834-836.

5. Friis-MÃ,ller A, Chen M, Fuursted K, Christensen SB, Kharazmi A (2002) In vitro antimycobacterial and antilegionella activity of licochalcone $A$ from Chinese licorice roots. Planta Med 68: 416-419.

6. Kuete V, Ngameni B, Mbaveng AT, Ngadjui B, Meyer JJ, et al. (2010) Evaluation of flavonoids from Dorstenia barteri for their antimycobacterial, antigonorrheal and anti-reverse transcriptase activities. Acta Trop 116: 100-104.

7. Sivakumar PM, Seenivasan SP, Kumar V, Doble M (2007) Synthesis, antimycobacterial activity evaluation, and QSAR studies of chalcone derivatives. Bioorg Med Chem Lett 17: 1695-1700.

8. Lin YM, Zhou Y, Flavin MT, Zhou LM, Nie W, et al. (2002) Chalcones and flavonoids as anti-tuberculosis agents. Bioorg Med Chem 10: 2795-2802.

9. Zhou B, He Y, Zhang X, Xu J, Luo Y, et al. (2010) Targeting mycobacterium protein tyrosine phosphatase B for antituberculosis agents. Proc Natl Acad Sci U S A 107: 4573-4578

10. Chiaradia LD, Mascarello A, Purificação M, Vernal J, Cordeiro MN, et al. (2008) Synthetic chalcones as efficient inhibitors of Mycobacterium tuberculosis protein tyrosine phosphatase PtpA. Bioorg Med Chem Lett 18: 6227-6230.

11. Mascarello A, Chiaradia LD, Vernal J, Villarino A, Guido RV, et al. (2010) Inhibition of Mycobacterium tuberculosis tyrosine phosphatase PtpA by synthetic chalcones: kinetics, molecular modeling, toxicity and effect on growth Bioorg Med Chem 18: 3783-3789.
12. Chiaradia LD, Martins PG, Cordeiro MN, Guido RV, Ecco G, et al. (2012) Synthesis, biological evaluation, and molecular modeling of chalcone derivatives as potent inhibitors of Mycobacterium tuberculosis protein tyrosine phosphatases (PtpA and PtpB). J Med Chem 55: 390-402.

13. Gond DS, Meshram RJ, Jadhav SG, Wadhwa G, Gacche RN (2013) In silico screening of chalcone derivatives as potential inhibitors of dihydrofolate reductase: Assessment using molecular docking, paired potential and molecular hydrophobic potential studies. Drug Invent 5: 182-191.

14. Yadav DK, Ahmad I, Shukla A, Khan F, Negi AS, et al. (2014) QSAR and docking studies on chalcone derivatives for antitubercular activity against $M$. tuberculosis H37Rv. J Chemom.

15. Patole J, Shingnapurkar D, Padhye S, Ratledge C (2006) Schiff base conjugates of $\mathrm{p}$-aminosalicylic acid as antimycobacterial agents. Bioorg Med Chem Lett 16: 1514-1517.

16. Hans RH, Guantai EM, Lategan C, Smith PJ, Wan B, et al. (2010) Synthesis antimalarial and antitubercular activity of acetylenic chalcones. Bioorg Med Chem Lett 20: 942-944.

17. Ahmad I, Thakur JP, Chanda D, Saikia D, Khan F, et al. (2013) Syntheses of lipophilic chalcones and their conformationally restricted analogues as antitubercular agents. Bioorg Med Chem Lett 23: 1322-1325.

18. Marrapu VK, Chaturvedi V, Singh S, Singh S, Sinha S, et al. (2011) Nove aryloxy azolyl chalcones with potent activity against Mycobacterium tuberculosis H37Rv. Eur J Med Chem 46: 4302-4310.

19. Sharma M, Chaturvedi V, Manju YK, Bhatnagar S, Srivastava K, et al. (2009) Substituted quinolinyl chalcones and quinolinyl pyrimidines as a new class of anti-infective agents. Eur J Med Chem 44: 2081-2091.

20. Barua N, Sarmah P, Hussain I, Deka RC, Buragohain AK (2012) DFT-based QSAR models to predict the antimycobacterial activity of chalcones. Chem Biol Drug Des 79: 553-559. 